\title{
GÊNEROS E SEXUALIDADES: ESTRATÉGIAS PARA PROMOÇÃ̃ DE DEBATES NA FORMAÇÃO DE PROFESSORES/AS
}

\author{
GÉNEROS Y SEXUALIDADES: ESTRATEGIAS PARA PROMOCIÓN DE \\ DEBATES EN LA FORMACIÓN DE PROFESORES/AS
}

\author{
Paula Regina Costa Ribeiro \\ UNIVERSIDADE FEDERAL DO RIO GRANDE \\ pribeiro.furg@gmail.com \\ JOANALIRA CORPES MAGALHÃES \\ UNIVERSIDADE FEDERAL DO RIO GRANDE \\ joanaliracm@yahoo.com.br \\ JULIANA LAPA RIZZA \\ UNIVERSIDADE FEDERAL DO RIO GRANDE \\ ju_rizza@yahoo.com.br
}

\section{RESUMEN}

En Brasil, las cuestiones de géneros y sexualidades han provocado debates y múltiples discusiones en diferentes instancias sociales y campos del saber. Una de las principales cuestiones es la presencia de estos temas en los espacios escolares y académicos. En este texto, tenemos como propósito presentar dos estrategias que se han mostrado eficaces en la promoción de este debate. Son estas: la disciplina "Géneros y sexualidades en los espacios educativos" y el "Video-curso Educación para la sexualidad: de los currículos escolares a los espacios educativos". A fin de pensar la aparición de estas temáticas en el escenario educativo brasileño, analizamos/trazamos algunas miradas en torno a políticas públicas que han posibilitado la emergencia y el reconocimiento de la problematización de las cuestiones de los géneros y de las sexualidades en el espacio escolar y académico. Presentamos también las dos estrategias que hemos acometido para la formación inicial y continuada de profesores/as, la disciplina y el Video-curso, destacando cómo hemos propiciado que las temáticas de los cuerpos, géneros, sexualidades, sexismo, misoginia, LGBTfobia, entre tantas otras, puedan ser debatidas como cuestiones que deben estar presentes en los currículos escolares y académicos. Creemos que, de esta forma, estaremos promoviendo la construcción de una escuela y universidad más plural que acoja a todos y a todas. 


\section{PALABRAS CLAVE}

Género, Sexualidad, Formación de profesores/as

\section{RESUMO}

No Brasil, as questões de gêneros e sexualidades têm provocado debates e muitas discussões por diferentes instâncias sociais e campos de saber. Uma das principais questões é a presença desses temas nos espaços escolares e acadêmicos. Nesse texto, temos como propósito apresentar duas estratégias que têm se mostrado potentes para a promoção desse debate, são elas: a disciplina "Gêneros e sexualidades nos espaços educativos" e o "Videocurso Educação para a Sexualidade: dos currículos escolares aos espaços educativos". A fim de pensarmos a emergência dessas temáticas no cenário educacional brasileiro, analisamos/traçamos olhares para algumas políticas públicas que possibilitaram a emergência e o reconhecimento da problematização das questões dos gêneros e das sexualidades no espaço escolar e acadêmico. Apresentamos também as duas estratégias que temos investido na formação inicial e continuada de professores/as, a disciplina e o Videocurso, destacando como temos propiciado que as temáticas dos corpos, gêneros, sexualidades, sexismo, misoginia, LGBTfobia entre tantas outras, possam ser debatidas como questões que devam estar presentes nos currículos escolares e acadêmicos. Acreditamos que desta forma estaremos promovendo a construção de uma escola e universidade mais plural que acolha todos e todas.

PALAVRAS-CHAVE

Gênero, Sexualidade, Formação de professores/as

\section{NOTAS INTRODUTÓRIAS}

Na contemporaneidade, temos percebido uma efervescência de discussões acerca das sexualidades e dos gêneros ${ }^{1}$. São diferentes instituições sociais -família, escola, instituição religiosa, entre outras- e campos de saber -Medicina, psicologia, educação, entre outros- que têm buscado explicar e debater esses temas. Conforme Autora (2013, 109) "Parece existir entre todos/as uma vontade de saber sobre os corpos, os prazeres, as sensações...".

\footnotetext{
1 Ao longo do texto utilizaremos as palavras gênero e sexualidade no plural, pois entendemos que existem múltiplas formas de vivermos os gêneros e as sexualidades. Entretanto, em alguns trechos do artigo as mesmas aparecerem no singular respeitando a escrita dos/as autores/as e dos documentos.
} 
No Brasil, é possível perceber alguns acontecimentos históricos, políticos e culturais que, articulados, ajudaram a compor esse cenário das sexualidades e dos gêneros sendo temas de debate na escola. Dentre estes acontecimentos, destacamos a implementação de políticas públicas, as quais possibilitaram que as questões como as sexualidades, os gêneros, a diversidade, os direitos humanos, a violência e a discriminação aos grupos sociais minoritários lésbicas, gays, bissexuais, as travestis e os/as transexuais (LGBT), mulheres, negros/as, indígenas, entre outros- estivessem presentes na escola.

Nos últimos anos percebe-se um retrocesso no que tange as discussões de gêneros e sexualidades no espaço escolar. Isso pode ser observado nas discussões do Plano Nacional de Educação (PNE - Lei número 13.005 de 2014) e também nos Planos Estaduais e Municipais de Educação, os quais retiraram esses temas, devido à pressão sofrida por parte de algumas instituições religiosas que lançaram uma ofensiva através do que intitularam como sendo uma "ideologia de gênero".

Entendemos que temas como estes não podem ficar às margens do currículo, ou ainda serem silenciados e invisibilizados se desejamos a promoção de uma escola plural em que se faça presente o reconhecimento das diferenças. Assim, temos buscado investir na formação inicial e continuada de professores/as da educação e de graduandos/as, para que questões como os corpos, os gêneros e as sexualidades estejam presentes nos currículos escolares e acadêmicos. Por esse viés, nessa escrita nosso objetivo é apresentar duas estratégias que têm se mostrado potentes para promoção desse debate: a disciplina "Gêneros e sexualidades nos espaços educativos" e o "Videocurso Educação para a Sexualidade: dos currículos escolares aos espaços educativos".

Para tanto, primeiramente apresentamos o referencial teórico que tem subsidiado nossos estudos e ações. Em seguida, traçamos um olhar para o cenário educacional brasileiro, a fim de pensarmos acerca das reformas que foram sendo propostas nesse campo, a partir de políticas públicas educacionais que possibilitaram a emergência e o reconhecimento da

\footnotetext{
${ }^{2}$ Esse termo vem sendo utilizado por alguns grupos sociais. Para Jimena Furlani (2015, grifos da autora) “O termo “ideologia de gênero’ NÃO ESTÁ PRESENTE, não é de uso no contexto das Teorias de Gênero. Esse termo, essa expressão, foi criada/inventada, recentemente, no interior de alguns discursos religiosos. Trata- se de uma INTERPRETAC,̃̃̃, EQUIVOCADA e CONFUSA, que não reflete o entendimento de 'Gênero' presente na Educação e na escolarização brasileiras, nas práticas docentes e/ou nos cursos de formação inicial e continuada de professoras/as".
} 
problematização das questões dos gêneros e das sexualidades no espaço escolar. Após, apresentamos as duas estratégias que temos investido na formação inicial e continuada de professores/as, a disciplina e o Videocurso. Finalizamos tecendo algumas considerações a fim de pensarmos a potencialidade dessas duas estratégias na formação de professores/as com o objetivo de promovermos uma educação para a sexualidade, seja no contexto escolar ou acadêmico.

\section{NOTAS TEÓRICAS}

A nosso modo e com nossos limites, temos o dever de nos apropriar - pela via do estudo - dos territórios e teóricos e com eles estabelecer interlocuções, ao mesmo tempo em que vamos reelaborando as teorias. Tais movimentos implicam em pôr os conceitos a funcionar, estabelecendo ligações possíveis entre eles, encaixando aqueles que têm serventia para o problema [...] e nos desfazendo daqueles que são inuteis (Corazza, 2002, 120).

Ao longo desses anos de atuação, temos buscado explorar territórios, estabelecer diálogos, tecer fios numa rede de relações, (re)significar teorias e fazer funcionar os conceitos a fim de fundamentar nossas ações no âmbito do ensino, da pesquisa e da extensão.

Nesta direção, temos promovido discussões nos espaços de formação inicial e continuada de professores/as, pautadas no campo teórico dos Estudos Culturais, pós-estruturalistas, e alguns pressupostos do filósofo Michel Foucault.

Os Estudos Culturais caracterizam-se por serem um campo de teorizaçãa e investigação que se utiliza de diversas disciplinas para estudar os processos de produção cultural da sociedade. Neste sentido, os Estudos Culturais não se constituem numa nova disciplina, mas são resultado da insatisfação com algumas disciplinas e seus proprios limites. Constituem-se, então, como um campo interdisciplinar, transdisciplinar e, algumas vezes, contra disciplinar, em que diversas disciplinas se interseccionam para investigar os aspectos culturais da sociedade contemporânea (Escosteguy, 1998; Nelson, Treichler \& Grossberg, 2008).

A cultura é entendida tanto como uma forma de vida - compreendendo ideias, atitudes, linguagens, práticas, instituições e estruturas de poder - quanto toda 
uma gama de práticas culturais: formas, textos, cânones, arquitetura, mercadorias produzidas em massa, e assim por diante (Nelson, Treichler \& Grossberg, 2008, 14).

Os Estudos Culturais estão preocupados com questões que se situam na conexão entre cultura, significação, posições de sujeitos e poder. A cultura está relacionada "com a produção e o intercâmbio de significados - o "dar e receber de significados" - entre os membros de uma sociedade ou grupo" (Hall, 1997, 02, [grifo do autor]). Por esse viés, conforme destaca Silva (2007, 133134), este campo de investigação concebe a cultura como um campo de luta em torno da significac,ão social.

A cultura é um campo de produção de significados no qual os diferentes grupos sociais, situados em posiç̃oes diferenciais de poder, lutam pela imposição de seus significados à sociedade mais ampla. [...] a cultura é um campo onde se define não apenas a forma que o mundo deve ter, mas também a forma como as pessoas e os grupos devem ser.

Hall (1997, 03 [grifos do autor]) argumenta que a cultura envolve todas as práticas que não se encontram simplesmente inscritas em nossa genética, mas que "nos transmitem valores, que precisam ser interpretados significativamente pelos outros, ou que dependem do significado para seu efetivo funcionamento". Assim, entendemos a representação como modo de produção de significados através da linguagem -sons, palavras escritas ou faladas, imagens eletrônicas ou impressas, notas musicais, objetos, gestos, entre outros- que representam para outras pessoas nossos conceitos, ideias, valores, pensamentos e sentimentos; que organizam e regulam as praticas sociais; que influenciam nossas condutas, modos de ser e estar na sociedade, ou seja, quem somos e a que grupo pertencemos; que demarcam e sustentam nossas múltiplas posições de sujeito (Hall, 1997, 3).

Por esse viés, entendemos que os sujeitos não possuem uma essência, unificada e acabada. Nas ações que promovemos buscamos problematizar que nossas múltiplas e cambiantes posições de sujeito são constituídas em meio à produção de significados -construídos por meio da linguagem- em torno da interseccionalidade de diversos marcadores sociais, como gêneros, raças, etnias, classes, religiões, sexualidades, geracionais, entre outros. Compreender esses processos, implicados em nossa constituição enquanto sujeitos plurais, nos possibilita perceber e discutir que são múltiplas, também, as formas como podemos construir os gêneros e as sexualidades. 
Assim, entendemos que os corpos, os gêneros e as sexualidades são produzidos, histórico e culturalmente, em meio a relações de poder-saber. Contudo, cabe ressaltar que, ao enfatizarmos o caráter construído dos gêneros e das sexualidades, não estamos negando a materialidade biológica dos corpos, ou argumentando que esta não tem importância, mas sim que buscamos problematizar as representações e construções que se apoiam nas características biológicas para justificar diferenças, desigualdades e posicionamentos sociais. Para Baukje e Meijer $(2002,158)$

Assim como nenhuma materialidade anterior está acessível a não ser através do discurso, também o discurso não consegue captar aquela materialidade anterior; argumentar que o corpo é um referente evasivo não equivale a dizer que ele é apenas e sempre construído. De certa forma, significa exatamente argumentar que há um limite à construtividade, um lugar, por assim dizer, onde a construção necessariamente encontra esse limite.

Ao considerarmos os corpos, os gêneros e as sexualidades como discursivamente construídos, acentuamos o fato de que existem muitas e conflitantes formas de definir e viver as feminilidades, as masculinidades, os desejos e os prazeres (Meyer, 2003). No entanto, conforme destaca Louro (2001, 72), é comum a sociedade considerar apenas uma forma de ser homem e apenas uma forma de ser mulher como normal; e aqueles ou aquelas que não se encaixam nesse padrão "são tidos como anormais, desviantes ou patológicos". Nesse sentido, a escola, a família, a religião, as mídias, as revistas, e outras instancias sociais, são espaços educativos importantes tanto para a legitimação e a valorização de alguns sujeitos e grupos, como para esconder ou rejeitar outros. Essa vertente teórica privilegia um debate sobre os gêneros e as sexualidades a partir de abordagens que enfocam a centralidade da linguagem na produção das relações que a cultura estabelece entre corpo, sujeito, conhecimento e poder.

Para Foucault (2007), saber e poder estão implicados, na medida em que não existe uma relação de poder sem que se constitua um campo de saber, assim como todo o saber constitui novas relações de poder. Neste sentido, o poder é produtivo e, para que ele se exerça por mecanismos sutis, faz-se necessário formar, organizar e circular um saber (Fonseca, 2003). O poder, para Foucault $(2007,183)$,

funciona e se exerce em rede. Nas suas malhas os indivíduos não só circulam mas estão sempre em posição de exercer este poder e de sofrer sua ação; nunca são alvo inerte ou consentido do poder, são sempre centros de transmissão. 
A partir desses pressupostos, temos buscado construir espaços de formação inicial e continuada de professores/as, a fim de tecermos e promovermos diálogos com esses sujeitos mediados por diferentes autoras e autores. Tais iniciativas têm sido muito potentes para pensarmos a educação para a sexualidade, pois nos permite entender os gêneros e as sexualidades como artefatos, invenções que se constituíram e se constituem na correlação de múltiplos elementos sociais presentes na família, medicina, educação, psicologia, entre outros.

\section{NOTAS SOBRE POLÍTICAS PÚBLICAS EDUCACIONAIS BRASILEIRAS}

No que tange a educação, foco sobre o qual recai esse estudo, desde o século XVIII é possível perceber a produção de uma teia discursiva acerca das sexualidades; a instituição pedagógica, por sua vez, "concentrou as formas do discurso neste tema; estabeleceu pontos de implantação diferentes; codificou os conteúdos e qualificou os locutores" (Foucault, 2007, 36). Sendo assim, nessa produção discursiva acerca das sexualidades, a escola emerge então como "uma das instituições nas quais se instalam mecanismos do dispositivo da sexualidade; através de tecnologias do sexo, os corpos dos estudantes podem ser controlados, administrados" (Altmann, 2001), por meio de estratégias de poder e saber.

Ao olharmos para a história, é possível percebermos na contemporaneidade, a partir de alguns elementos (dentre eles as políticas públicas, programas e ações governamentais em diferentes esferas - federais, estaduais e municipais , entre outros), a emergência de um cenário de discussões acerca das sexualidades e dos gêneros em instituições educacionais. Nos últimos tempos, essas discussões têm se apresentado de forma mais acentuada devido a alguns movimentos governamentais; por exemplo, algumas políticas educacionais que têm abordado a importância do debate dessas temáticas na educação. Dentre elas destacamos algumas sobre as quais, nesta escrita, vamos empreender algumas discussões: a Lei número 9.394/96 que estabelece as Diretrizes e Bases da Educação Nacional (LDB); o Parâmetro Curricular Nacional (PCN) no eixo transversal orientação sexual (1997); o Plano Nacional de Educação (PNE), Lei número 010172/01; as Diretrizes Curriculares Nacionais para a Formação de Professores da Educação Básica, em nível superior, curso de licenciatura e de graduação, Resolução CNE/CP $\mathrm{N}^{\mathrm{o}}$ 1, de 18 de Fevereiro de 2002; as Diretrizes Curriculares Nacionais para o Ensino Médio, Resolução $\mathrm{n}^{\circ}$ 2, de 30 de Janeiro 2012; a Resolução $\mathbf{n}^{\circ} 1$ de 30 
de maio de 2012, que estabelece Diretrizes Nacionais para a Educação em Direitos Humanos, e as duas políticas mais recentes, o Plano Nacional de Educação (PNE), Lei número 13.005/14 e as novas Diretrizes Curriculares Nacionais para a formação inicial em Nível Superior (cursos de licenciatura, cursos de formação pedagógica para graduados e cursos de segunda licenciatura) e para a formação continuada, Resolução $\mathrm{n}^{\circ} 2$, de $1^{\circ}$ de Julho de 2015.

Em nossas ações temos buscado olhar para as políticas educacionais que apresentam as temáticas das sexualidades e dos gêneros, com o objetivo de discutir os efeitos que os discursos presentes nesses documentos têm produzido na contemporaneidade. É importante destacar que centramos nossos esforços em materiais que datam da década de $1990 \mathrm{em}$ diante. Esse recorte histórico apresenta importantes legislações e reformas educacionais; sendo assim, é a partir dessa década que as discussões sobre as sexualidades e os gêneros e o entrelaçamento com a educação emergiram de forma mais acentuada.

Partimos da "Lei de Diretrizes e Bases da Educação", Lei nº 9394 de 1996, a qual segue em vigor até os dias atuais. Com relação às discussões acerca das sexualidades e dos gêneros, não encontramos um artigo que diretamente apresentasse alguma proposição para que essas temáticas estejam presentes na escola, ou a importância de serem debatidas com crianças e adolescentes.

Com relação à discussão acerca da tolerância, no Art. $3^{\circ}$, no qual são determinados os princípios sobre os quais o ensino será ministrado, ela é mencionada no inciso IV: "respeito à liberdade e apreço à tolerância" (Brasil, 1996). Em outro momento, no Art. $32^{\circ}$ que objetiva a formação do cidadão e da cidadã durante os nove anos do Ensino Fundamental, também no inciso IV, a tolerância é ressaltada: “o fortalecimento dos vínculos de família, dos laços de solidariedade humana e de tolerância recíproca em que se assenta a vida social" (Brasil, 1996).

Essa questão da tolerância emerge a partir da noção do multiculturalismo ${ }^{3}$, de um movimento de reivindicação advindo de grupos sociais marginalizados, por possuírem uma cultura e uma forma de vida diferente da considerada

\footnotetext{
${ }^{3}$ É importante destacar que existem diferentes visões acerca dessa questão. A perspectiva liberal ou humanista está pautada nas ideias de tolerância, respeito e convivência em harmonia entre as diferentes culturas. A perspectiva crítica, por sua vez, entende que a ideia de tolerância coloca aquele que tolera como superior nessa relação, assim como o respeito, que parece trazer consigo uma essência, ou seja, as diferenças entre as culturas são fixas e nos resta apenas respeita-las (SILVA, 2007).
} 
legítima, e que passaram a lutar para terem suas culturas reconhecidas e valorizadas (Silva, 2007). Assim como o proposto na LDB em 1996 e com ressonâncias contemporâneas, a tolerância e o respeito às diferentes culturas, ou ainda como hoje ouvimos dizer, à diversidade, parecem ser abordagens centrais no campo educacional; ou diríamos ainda, parecem produzir uma pedagogia oficial. Segundo Silva, "a posição socialmente aceita e pedagogicamente recomendada é de respeito e tolerância para com a diversidade e a diferença" (Silva, 2014, 73).

Embora que, em algumas vezes, quando é utilizada a palavra diversidade em outras políticas educacionais como sinônimo de diferença, e ainda que existam alguns esforços em produzir essa aproximação, ambos conceitos apresentam implicações conceituais e não podem ser tomados como sinônimos quando carregam significados distintos. Enquanto que as políticas pautadas na diversidade promovem a tolerância para com a diferença, a pedagogia da diferença, por sua vez, "estimula a diferença que se recusa a se fundir com o idêntico" (Silva, 2014, 101).

Outro documento que a LDB menciona são os temas transversais, presentes nos "Parâmetros Curriculares Nacionais" (PCN), os quais chegam às escolas em 1997, logo após a LDB. Dentre as reformas educacionais que perpassaram as escolas brasileiras, no que tange o debate acerca das sexualidades e dos gêneros, o PCN apresenta-se como um marco na história dessa incorporação da discussão da sexualidade nas políticas públicas de educação. Foi por meio do PCN que a sexualidade "apareceu oficialmente integrando o currículo por meio da transversalidade" (Autora, 2013, 13). No entanto, é importante ressaltar que são apenas algumas referências/diretrizes para a organização curricular, não se caracterizando enquanto uma política que institui a obrigatoriedade, por exemplo, da discussão da sexualidade na escola.

No tema transversal relacionado à orientação sexual, as problematizações em torno da sexualidade buscam ir além de abordagens de cunho terapêutico, psicológico ou higienista apenas. A orientação sexual proposta pelo PCN busca enfocar "as dimensões sociológica, psicológica e fisiológica da sexualidade" (Brasil, 1997).

O PCN recolocou a discussão da sexualidade nas escolas, e esse movimento foi uma estratégia para aumentar o controle exercido sobre os comportamentos sexuais dos indivíduos, não mais sobre o "homem-corpo, mas do homemespécie" (Foucault, 2005, 289), enquanto massas globais que constituem uma população. Por meio desses mecanismos regulamentadores da população nesse caso as proposições advindas com os PCN - passou-se a exercer um 
poder que visava gerenciar condutas, regulando e gerindo a sexualidade e produzindo uma arte de governar. O objetivo dos PCN é promover "uma maior conscientização da importância da saúde e da necessidade de ações não só curativas mas também preventivas" (Brasil, 1997), ou seja, são ações educativas que visam o governo das condutas de uma população.

Outro documento que buscamos analisar foi o primeiro "Plano Nacional de Educação", que vigorou dos anos de 2001 a 2010. Embora com alguns problemas na sua execução, esse PNE apresentou importantes contribuições para que as questões das sexualidades e dos gêneros estivessem presentes nos currículos escolares.

No Ensino Fundamental o foco recaiu sobre o livro didático e a implementação de um programa de avaliação desse material, para que fossem estabelecidos "critérios a adequada abordagem das questões de gênero e etnia e a eliminação de textos discriminatórios ou que reproduzam estereótipos acerca do papel da mulher, do negro e do índio" (Brasil, 2001). Já no âmbito do Ensino Superior, o gênero é mencionado em dois momentos, nos objetivos e metas de número 12 , que propõem a problematização, nos cursos de formação de professores/as, dos temas transversais - dentre eles a educação sexual e o gênero -, e na meta número 31 que indica a inclusão de questões referentes à políticas de gênero no questionário anexo ao Exame Nacional de Cursos, como por exemplo, o trancamento e/ou abandono de um curso de graduação devido a uma gravidez ou cuidado e guarda dos/as filhos/as.

Por fim, o gênero aparece nas diretrizes para o magistério da Educação Básica, que propõem: "Inclusão das questões relativas à educação dos alunos com necessidades especiais e das questões de gênero e de etnia nos programas de formação" (Brasil, 2001c).

A partir dessas proposições presentes nesse primeiro PNE é possível perceber que já havia um investimento por parte do governo, através de políticas públicas educacionais, em pensar os gêneros e as sexualidades integradas ao currículo das escolas. Além disso, são pensadas ações para o Ensino Superior, vislumbrando os cursos de formação de professores/as como um espaço profícuo para promover tais problematizações, já que esses/as licenciandos/as serão, futuramente, os professores/as da Educação Básica e também do Ensino Médio.

No ano de 2002 são instituídas as "Diretrizes Curriculares Nacionais para a Formação de Professores da Educação Básica, em nível superior, em curso de 
licenciatura e de graduação plena", que apresentam alguns princípios e fundamentos que deverão ser observados e seguidos na organização estrutural e curricular das instituições educacionais. Essas diretrizes propõem no Art. $2^{\circ}$, que no que tange à organização curricular, que as instituições de ensino deverão estar atentas às orientações para formação da prática pedagógica docente e, dentre elas, o que está disposto no inciso II: "o acolhimento e o trato da diversidade" (Brasil, 2002).

A palavra diversidade, e algumas vezes também a diferença, tem estado presente de forma recorrente em algumas políticas educacionais. Para o autor Junqueira $(2014,4)$, a diversidade parece ter se tornado uma palavra de ordem, ainda mais após ganhar a arena política, mas é importante que possamos refletir acerca de alguns aspectos, tais como: "De que e de quem estamos falando? Quem ficou de fora? Alguém ficou mais ao centro ou mais à margem? De que modo são representadas diferentes categorias sociais nos discursos acerca da diversidade?".

Assim, é importante destacar que para pensar uma educação para as relações étnico-raciais, para a diferença e para as necessidades das pessoas com deficiência, ou seja, produzir uma política educacional inclusiva, é preciso um "investimento permanente em favor da subversão dos valores hegemônicos e das relações de poder que nortearam a estruturação dessa escola" (Junqueira, $2014,6)$. Não basta apenas pensar na promoção e respeito para com a diferença, se os/as professores/as não estiverem dispostos/as "a romper os seus compromissos com uma educação normalizadora, (re)produtora e reiteradora dos ditames do classismo, da branquitude, da heteronormatividade, da corponormatividade, etc." (Ibid., 2014, 7).

Em 2012, foram promulgadas as "Diretrizes Curriculares Nacionais para o Ensino Médio", por meio da Resolução $\mathrm{n}^{\circ}$ 2, de 30 de Janeiro daquele ano. Dentre as proposições presentes neste documento ressaltamos o Art. 16, o qual destaca os aspectos que o projeto político-pedagógico das escolas de Ensino Médio deve considerar. $\mathrm{O}$ inciso XV propõe a:

valorização e promoção dos direitos humanos mediante temas relativos a gênero, identidade de gênero, raça e etnia, religião, orientação sexual, pessoas com deficiência, entre outros, bem como práticas que contribuam para a igualdade e para o enfrentamento de todas as formas de preconceito, discriminação e violência sob todas as formas (Brasil, 2012). 
A construção do Projeto Político Pedagógico possibilita a constituição de uma identidade institucional. Isto significa resgatar a escola como espaço público, lugar de diálogo, fundado na reflexão coletiva.

Assim, articular a discussão dos gêneros e das sexualidades aos princípios, diretrizes e propostas que regem o processo educacional dessa instituição é possibilitar que essas temáticas sejam discutidas de forma permanente e sistemática, sendo uma preocupação de toda a comunidade escolar e acadêmica.

Entendemos que o Projeto Político Pedagógico (PPP) de uma escola é o documento que organiza o processo educacional dessa instituição. É um plano/projeto que está entrelaçado às questões sociais, históricas, culturais e econômicas, por isso é político, ou seja, ocupa-se de pensar a constituição dos sujeitos, cidadãos/ãs da sociedade e desenvolve-se atrelado a questões educacionais.

Dessa forma, incluirmos estas temáticas no currículo escolar constitui-se como uma estratégia que poderá contribuir para a minimização destes binarismos, dos estigmas, representações e preconceitos atribuídos aos sujeitos desviantes da norma, contribuindo assim para o reconhecimento da pluralidade sexual e dos gêneros.

Outro documento que buscamos analisar são as "Diretrizes Nacionais para a Educação em Direitos Humanos", sancionada em 30 de maio de 2012, cuja proposta é a inserção da educação em direitos humanos nos currículos escolares por meio da transversalidade, da disciplinaridade ou, ainda, pela articulação entre essas duas formas de abordagem. Segundo o Art. $6^{\circ}$, as escolas com seus Projetos Políticos Pedagógicos (PPP), seus Regimentos Escolares; e no Ensino Superior, os Planos de Desenvolvimento Institucional (PDI), os programas pedagógicos dos cursos de graduação, os materiais didáticos pedagógicos utilizados no ensino, na pesquisa e na extensão, os aspectos relacionados à gestão e aos processos avaliativos, deverão contemplar a educação em direitos humanos de forma transversal.

No âmbito do Ensino Superior, essas Diretrizes apresentam um avanço significativo, já que no Art. 9": "A Educação em Direitos Humanos deverá estar presente na formação inicial e continuada de todos(as) os(as) profissionais das diferentes áreas do conhecimento" (Brasil, 2014a). Além disso, outro aspecto importante está presente no Art. $12^{\circ}$, o qual apresenta a seguinte proposição: 
Art. 12. As Instituições de Educação Superior estimularão ações de extensão voltadas para a promoção de Direitos Humanos, em diálogo com os segmentos sociais em situação de exclusão social e violação de direitos, assim como com os movimentos sociais e a gestão pública (Brasil, 2012).

Com esse artigo, a proposta é que a educação em direitos humanos ultrapasse os muros das instituições de educação formal, atingindo outros segmentos da sociedade por meio das ações advindas com a extensão promovida pelas instituições de Ensino Superior.

As diretrizes apresentam também alguns princípios sobre os quais a educação em direitos humanos se fundamenta, dentre eles o "reconhecimento e valorização das diferenças e das diversidades" (Brasil, 2012). Nesse sentido, embora as diretrizes se proponham a pensar as diferenças, ao mencionarem as diversidades é preciso termos cuidado para não cairmos na armadilha de promover a diferença, mas com um sentimento de benevolência, ou seja, de tolerância. Dessa forma não estaremos promovendo uma pedagogia da diferença, mas sim produzindo outras dicotomias, como a identidade hegemônica que respeita a identidade subalterna, ou a atribuição da diferença do outro a problemas psicológicos, ou ainda trabalhar com uma abordagem do outro como aquele que é exótico.

Dentre as políticas educacionais que apresentam reformas educacionais, uma das mais recentes é o "Plano Nacional de Educação" (PNE), Lei no 13.005, de 25 de junho de 2014. Esse plano, assim como o anterior, também tem vigência de 10 anos, e é composto de 20 metas, sendo que em cada uma delas são descritas algumas estratégias para que as metas propostas sejam atingidas.

Nos artigos dessa Lei é possível perceber as ressonâncias das Diretrizes Nacionais para a Educação em Direitos Humanos, pois são mencionadas no PNE (2014-2024) questões como promoção da cidadania, respeito aos direitos humanos e à diversidade cultural e a erradicação de todas as formas de preconceito e discriminação, que estão presentes nas diretrizes do plano. Essas questões aparecem sendo fortemente debatidas em estratégias que objetivam atingir as metas que visam o aumento de matrículas e também de concluintes, tanto no Ensino Fundamental quanto no Ensino Superior.

Os grupos sociais historicamente desfavorecidos, que sofrem com situações de discriminação, preconceito e violência, adquiriram destaque nessa política pública quando pensados o ingresso, a permanência e até mesmo a qualidade 
da educação, como é possível perceber na estratégia 2.4 da meta 2, 3.8 e 3.13 da estratégia 3, e 12.9 da estratégia 12. A evasão escolar já nos primeiros anos do Ensino Fundamental ainda se apresenta com um número significativamente alto e, além disso, a não presença de negros/as, travestis, transexuais, índios, entre outros segmentos sociais, no Ensino Médio e mais ainda nas universidades, parece que foram as motivações para que nesse PNE fossem pensadas políticas que garantissem a inserção e permanência desses sujeitos nas escolas - e para isso são necessárias ações que visem a minimização e/ou a erradicação de todas as formas de discriminação e violência.

A fim de possibilitar que na escola tenhamos a presença de sujeitos pertencentes a diferentes grupos sociais, ou seja, ter uma participação proporcional, o PNE propõe "a adoção de políticas afirmativas, na forma da lei" (Brasil, 2014). Esse movimento já vem sendo pensando desde a criação da Secretaria De Educação Continuada, Alfabetização, Diversidade E Inclusão

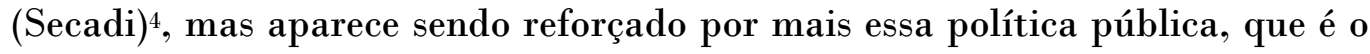
PNE. Dentre as ações afirmativas que já têm sido implementadas, podemos destacar as leis de cotas para o ingresso de negros, índios e estudantes de escolas públicas nas universidades. Essa lei tem possibilitado que nos bancos das universidades tenhamos uma distribuição proporcional de grupos sociais, e que essa modalidade de ensino não se caracterize como um espaço elitizado, mas sim como um lugar para todos e todas.

Embora o PNE apresente problematizações importantes acerca de políticas afirmativas de inclusão e promoção dos direitos humanos, é importante ressaltar que antes dessa lei ser sancionada houve um caloroso debate sobre a questão dos gêneros, tema que estava contemplado no plano, mas que foi retirado após votação na Câmara de Deputados.

Dentre as políticas educacionais apresentadas e debatidas nesta escrita, o que temos de mais recente e também inovador, ou seja, onde os princípios propostos apresentam de forma pontual e significativa a importância do debate das questões dos gêneros e das sexualidades na formação de

\footnotetext{
${ }^{4}$ É importante ressaltar que essa secretaria, que representa princípios de cidadania, inclusão e combate a todas as formas de discriminação, e que era responsável por implementar políticas nas áreas de educação de jovens e adultos, educação ambiental, educação em direitos humanos, educação especial, do campo, escolar indígena, quilombola e educação para as relações étnico-raciais, foi recentemente extinta, marcando assim um verdadeiro contrassenso político e administrativo e, talvez, um retrocesso no caminho da construção de uma sociedade mais justa.
} 
professores/as, são as "Diretrizes Curriculares Nacionais" para a formação inicial em nível superior (cursos de licenciatura, cursos de formação pedagógica para graduados e cursos de segunda licenciatura) e para a formação continuada.

Nas proposições apresentadas por essas diretrizes, as discussões acerca dos gêneros e das sexualidades estão presentes em quatro momentos do documento, sendo que há uma ampliação para as outras questões que permeiam a produção da identidade dos sujeitos; ou seja, fala-se também em raça e etnia, faixa geracional, diferença religiosa, pessoas com deficiência, entre outros aspectos relacionados à demarcação e ao reconhecimento da diferença. As discussões estão presentes nos seguintes momentos: Capítulo I das disposições gerais; Capítulo II - formação dos profissionais do magistério para educação básica: base comum nacional; Capítulo III - do(a) egresso(a) da formação inicial e continuada e o Capítulo V - da formação inicial do magistério da educação básica em nível superior: estrutura e currículo (Brasil, 2015).

A partir desses capítulos a proposta é que, no tocante ao projeto de formação inicial e continuada de professores/as e em articulação com o sistema de educação básica, seja estabelecido um regime de colaboração, envolvendo fóruns estaduais e distrital permanentes, assegurando uma base comum nacional para cursos de primeira ou segunda licenciatura, e ainda a formação continuada de professores/as, que deverá garantir nos currículos - além de outras questões, seus fundamentos e metodologias - direitos humanos, diversidades étnico-raciais, de gêneros, sexuais, religiosas, geracionais, entre outros.

Sabemos que política pública não é garantia de que o debate será promovido, mas ela apresenta-se como elemento importante nessa tessitura em que a demarcação de territórios torna-se imprescindível, ainda mais na atual conjuntura em que nosso país, o Brasil, está vivendo, de forte conservadorismo e discursos religiosos dominando o debate da proposição e implementação de políticas educacionais.

Ao problematizarmos algumas políticas púbicas, não tivemos como proposta apenas rememorar a partir de fatos presentes na história o que se tem pensado acerca da educação e seus atravessamentos com os gêneros e as sexualidades, ou seja, produzir a história dessa articulação. Ao contrário, buscamos compreender os movimentos que foram acontecendo e que possibilitaram a visibilidade do debate dessas temáticas na formação inicial e continuada de 
professores/as - os quais podem ser apontados como uma estratégia que possibilitou a ampliação da discussão das temáticas da sexualidade na escola, mobilizando nosso pensamento a fim de suscitar maneiras para promoção dessa discussão.

\section{NOTAS PARA A FORMAÇÃO DE PROFESSORES/AS E GRADUANDOS/AS}

Nas nossas diversas atividades de ensino, pesquisa e extensão, buscamos problematizar as desigualdades de gênero, sexuais e étnico-raciais, estimulando o espírito investigativo, a curiosidade e a criatividade, valorizando o convívio social, o pluralismo e o respeito às singularidades dos sujeitos. Entendemos que a escola e a universidade são espaços privilegiados para a discussão sobre a diversidade, a diferença e a produção das identidades de gênero e sexuais, visando assim contribuir para uma sociedade mais plural e democrática. Acreditamos que a discussão dessas questões possibilita a desconstrução dos modelos hegemônicos e naturalizados de se compreender e viver a sexualidade, entendendo que os discursos que falam sobre a sexualidade são construções sociais, históricas e culturais e que essa teia discursiva contribui para a produção dos sujeitos.

Nesse sentido, temos investido em cursos de formação inicial e continuada de professores/as da educação e graduandos/as, para que essas temáticas estejam presentes tanto no currículo escolar como no acadêmico. Dentre as atividades, destacamos a disciplina "Gêneros e Sexualidades nos Espaços Educativos" e o Videocurso "Educação para a sexualidade: dos currículos escolares aos espaços educativos", que apresentamos a seguir.

\subsection{Disciplina Gêneros e Sexualidades nos Espaços Educativos}

No ano de 2012, dando continuidade à proposta de enveredar por outros caminhos que potencializassem a formação de professores/as no campo da Educação para a Sexualidade, emergiu a proposta de criação da disciplina "Gêneros e Sexualidades nos Espaços Educativos". O desejo era promover um espaço em que os cursos de graduação da universidade, independentemente de ser licenciatura, bacharelado ou ainda tecnólogo, pudessem estar pensando e discutindo as questões de gêneros e sexualidades. 
Suscitar novos acontecimentos, isto é, pensar outras experiências para além do que é instituído nos currículos oficiais dos cursos de graduação, por meio de uma disciplina que discutisse temáticas que muitas vezes não estão nos programas curriculares (como as questões de corpos, gêneros e sexualidades) mas que na contemporaneidade, atraves de várias condições sociais, politicas e culturais, conjugaram-se e articularam-se na produção da visibilidade de tais temáticas; além de possibilitarem importantes e instigantes análises e teorizações.

Como seria propor para todos os cursos de graduação da universidade uma disciplina que problematizasse os gêneros, as sexualidades, as relações étnicoraciais, o sexismo, a homofobia, o racismo, as novas configuraç̃os familiares, os corpos, os prazeres, dentre tantas outras questões? A partir do pensador Michel Foucault entendemos que propor esse outro espaç-tempo nos cursos de graduação seria uma possivel heterotopia, um lugar real, que para Gallo (2007, 100) significaria não criar um novo modelo, "mas simplesmente formas outras de fazer e viver, no contexto mesmo daquele modelo instituído".

Que argumentos teríamos para propor nesse outro espaço que possibilitasse "viver o ato educativo como acontecimento" (Gallo, 2007, 101) na universidade? Elencamos alguns deles: a universidade como um espaço privilegiado para discutir essas temáticas; ações do Ministério da Educação para a inclusão dessas questões nos currículos escolares e universitários; as discussões propostas pelo eixo Orientação Sexual presente nos Parâmetros Curriculares Nacionais que emergiram na década de 1990; os projetos de lei que têm surgido na contemporaneidade e que passaram a enfocar tais temas; o aumento da violência sexista, racial e homofóbica; as novas identidades que têm se apresentado nas escolas e universidades, como os/as travestis e os/as transexuais e a utilização do nome social.

A fim de podermos conhecer outras experiências, ou seja, outros temposespaços que discutissem essas questões, realizamos um levantamento para conhecer quais universidades federais do Brasil elencadas no site do MEC estavam oferecendo disciplinas sobre essas temáticas. Esse levantamento nos possibilitou verificar a ocorrência, nas 44 universidades federais em tivemos acesso aos currículos dos cursos ofertados, a oferta de disciplinas em diferentes 82 cursos de graduação, sendo que 39 deles oferecem mais de uma disciplina. Nos restantes 43 cursos encontramos apenas uma disciplina de sexualidade sendo ofertada (Autora, 2015). 
Após essa análise, apresentamos a proposta de criação da disciplina "Gêneros e Sexualidades nos Espaços Educativos" para a Pró-Reitoria de Graduação e para o Instituto de Educação, no qual a disciplina ficaria lotada. Após esse movimento, também foi necessário apresentar a disciplina para todos/as os/as coordenadores/as dos cursos de graduação da FURG, para que, dessa forma, pudessem conhecer a proposta e também solicitar vagas para matrículas de alunos/as nos seus cursos.

Assim, participamos de uma reunião organizada pela Pró-Reitoria de Graduação, com os seguintes propósitos: apresentar as características da disciplina, além de informar que não é uma disciplina para as licenciaturas e sim para todos os cursos. Nesse sentido, foi preciso problematizar o entendimento de espaços educativos, expressão presente na nomenclatura da disciplina, como aqueles locais que ensinam e possuem uma pedagogia, ou seja, espaços sociais implicados na produção e no intercâmbio de significados, tais como: universidade; escola; mídia; instituições religiosas, jurídicas, de saúde e de trabalho, entre outros.

A disciplina vem sendo desenvolvida com a carga horária de três horas/aula, 45 créditos, e a oferta se dá na modalidade optativa para os cursos que já fizeram suas reformulações curriculares e inseriram essa disciplina na grade de ofertas de disciplinas optativas. Para os cursos que ainda não fizeram ou que não apresentaram interesse em inserir essas discussões na grade curricular, os/as alunos/as podem cursar a disciplina por meio da solicitação de matrícula complementar, a qual será computada no histórico do/a estudante como horas complementares, exigência dos cursos de graduação.

Nesse sentido, como proposta de discussão, a disciplina apresenta a seguinte ementa: Discussão e análise de temáticas a respeito das questões dos corpos, gêneros e sexualidades na contemporaneidade, enfocando o ensino e aprendizagem dessas questões nos diversos espaços educativos. Análise do processo de produção dessas temáticas nas distintas instâncias sociais e pedagogias culturais.

A disciplina é ofertada para todos os cursos da FURG desde o segundo semestre de 2012 e já participaram acadêmicos/as dos seguintes cursos: Ciências Biológicas Licenciatura/Bacharelado, Letras - Português, Letras Português/Espanhol, Letras Português/Inglês, Pedagogia/Licenciatura, Artes Visuais/Licenciatura e Bacharelado, Engenharia Civil, Engenharia Mecânica, Geografia, Psicologia, Arquivologia, Arqueologia, Administração, Educação 
Física, História, Oceanologia, Economia, Educação Física, Direito, Medicina, História Licenciatura/Bacharelado e Biblioteconomia.

Na organização da disciplina, buscamos levar em consideração as discussões propostas pelo autor Gallo (2007, 101), ou seja, não deixar de lado qualquer planejamento, mas sim "planejar o ponto de partida, mas sem prever e planejar de antemão o ponto de chegada". Dessa forma, organizamos algumas discussões que serão promovidas na disciplina, mas não encerramos as discussões em uma única teia discursiva, ou seja, abrimo-nos para o que acontece em sala de aula "para além do planejado, do planificado, dos objetivos definidos de antemão". O referencial teórico da disciplina está alicerçado nos Estudos Culturais nas suas perspectivas pós-estruturalistas.

Para tanto, essas problematizações estão organizadas a partir de quatro eixos temáticos - diversidades, corpos, gêneros e sexualidades. As discussões em torno desses eixos têm se estabelecido por meio das aulas presenciais e também através dos espaços virtuais, os quais têm se apresentado como potentes estratégias para o processo de aprendizagem, ampliação e aprofundamento dos debates. Nesses espaços - presencial e virtual discutimos as dúvidas, sugerimos materiais, compartilhamos experiências vividas em diferentes instâncias, como família, universidade, mídia, grupo de amigos/as, entre outras, a respeito das temáticas desenvolvidas.

No Eixo Diversidade buscamos discutir a multiplicidade de ideias, linguagens, religiões, costumes, comportamentos, valores, classes, nacionalidades, crenças, etnias, gêneros e sexualidades que constituem os sujeitos. Argumentamos que vivemos nossa subjetividade em um contexto social, no qual a linguagem e a cultura dão significado à experiência que temos de nós mesmos.

No Eixo Gênero enfocamos sobre os estudos feministas e de gênero, apresentando os deslocamentos desse conceito. Discutimos que o conceito emerge em meio a contextos políticos, sociais, históricos e econômicos. Debatemos que as masculinidades e as feminilidades, diferentemente do que algumas correntes defendem, não são constituídas propriamente pelas características biológicas, mas são o produto de tudo o que se diz ou se representa dessas características

No Eixo Corpo problematizamos os corpos como produções híbridas biológicas, históricas e culturais-, que estão constantemente sendo modificadas e (re)significadas em função das diversas formas com que estes 
têm sido pensados, narrados, interpretados e vividos ao longo do tempo pelas diferentes culturas.

No Eixo Sexualidade discutimos sobre as várias perspectivas que a sexualidade vem sendo estudada: determinismo biológico - a sexualidade é universal e biologicamente determinada; essencialismo biológico - a sexualidade é reduzida a uma essência interior, uma pulsão; e o construcionismo social. Debatemos a sexualidade em outra perspectiva, na qual ela é tomada como produzida nos acontecimentos históricos e culturais das experiências das pessoas, ao correlacionar nos corpos comportamentos, linguagens, representações, crenças e posições de sujeito.

Na disciplina nos deixamos levar pelas vivências, anseios e desejos dos/as alunos/as que participam da mesma, construindo assim uma experiência pedagógica de forma a possibilitar que assuntos que estão na ordem do discurso - como por exemplo a Lei Maria da Penha, cotas para ingresso na universidade, as normativas para a utilização do nome social, as mudanças e intervenções corporais, como tatuagens, piercing, branding, o abuso e a violência sexual, a homofobia, o sexting, entre outros temas-emergissem nas discussões propostas.

Desta forma, a cada oferta da disciplina, outros olhares, outros sujeitos, outras histórias, outras narrativas têm sido produzidas possibilitando repensarmos, desestabilizarmos e borrarmos algumas fronteiras instituídas e discursos naturalizados - a masculinidade, a heterossexualidade, a heteronormatividade, a criança inocente e assexuada, o/a adolescente com a sexualidade aflorada, a família nuclear, entre tantos outros presentes na sociedade - possibilitando que os/as acadêmicos/as façam o contraponto, reflitam e discutam tais questões.

\subsection{Apresentando o Videocurso EducaÇão Para a SEXualidade}

No ano de 2015, implementamos o "Videocurso Educação para a Sexualidade: dos currículos escolares aos espaços educativos", sendo este uma nova estratégia que estamos desenvolvendo totalmente online (www.videocursosexualidade.com.br). O Videocurso tem como objetivo contribuir para a formação de profissionais da educação, por meio de videoaulas que abordam temáticas de corpos, gêneros e sexualidades nas escolas e nos diversos espaços educativos. O Videocurso também tem como 
campo de estudos os Estudos Culturais nas suas perspectivas pósestruturalistas.

O Videocurso está organizado em onze (11) videoaulas que tratam de temáticas como: os gêneros, as sexualidades, sexting, aids, mídia, violência sexista e homofóbica, entre outros temas. Todas as videoaulas são acompanhadas de material de apoio para o melhor entendimento das temáticas em questão. Os/as cursistas também têm acesso a uma midiateca com muitas referências bibliográficas, bem como um glossário que apresenta muitos termos a fim de subsidiar o/a cursista. As videoaulas são:

1. Educação para a sexualidade: apontamentos teóricos e conceituais. A proposta dessa videoaula é discutir a expressão educação para a sexualidade, adotada pelo GESE apresentando algumas definições construídas ao longo do tempo.

2. Educação para a sexualidade: contexto histórico. Nesta videoaula revisitamos a história da educação para a sexualidade no Brasil a fim de conhecer os movimentos históricos, sociais e culturais que ocorreram para que o debate das temáticas de corpos, gêneros e sexualidades estivesse presente no espaço escolar.

3. Identidade e diferença: potencialidades para o debate da diversidade. A proposta desta videoaula é problematizar o conceito de diversidade e sua inter-relação com os conceitos de identidade e diferença.

4. Identidades de gênero: masculinidades, feminilidades e suas múltiplas possibilidades. Nesta videoaula discutimos sobre as identidades de gênero, buscando problematizar o conceito de gênero e como essa definição vem se reconfigurando. Também são abordados alguns termos como travesti e transexual.

5. Identidades sexuais: refletindo sobre diferentes posições de sujeito. Trazemos nesta videoaula algumas problematizações sobre o conceito de identidade, bem como discussões sobre as identidades sexuais, isto é, a heterossexualidade, a bissexualidade, a homossexualidade e a assexualidade.

6. Violência de gênero: sexismo e homofobia em destaque. A proposta desta videoaula é ampliar nossos olhares sobre a violência de gênero. Entendemos que ela está presente nas relações de homens e mulheres e nas suas múltiplas facetas, as quais vamos destacar o sexismo e a homofobia. 
7. Corpos em Foco: marcadores, inscrições, subjetivações. Nesta videoaula falamos sobre os corpos, suas marcas e como somos posicionados a partir delas. Problematizamos os conceitos de organismo e corpo, para assim, apresentar o conceito de corpo biossocial. Discutimos também os marcadores corporais de gênero e sexualidade e como eles são socialmente (re)produzidos.

8. Aids: entendimentos e atualizações. Temas como HIV, aids e os cuidados com o corpo são pauta dessa videoaula, que tem como propósito estudarmos um pouco sobre tais temáticas o HIV e aids, seus conceitos e atualizações.

9. Sexualidades, Gêneros e Mídias: discutindo os artefatos culturais como espaços educativos. Nesta videoaula, problematizamos a forma como os gêneros e as sexualidades são representadas e (re)construídas em diferentes espaços, destacando-se as mídias. Assim, buscamos através de diferentes artefatos culturais -vídeos, charges, desenhos, revistas, filmes, entre outrosabordar essas temáticas.

10. Sexting: algumas definições, possibilidade e discussões. Vamos conversar nessa videoaula sobre uma nova prática, o sexting, que vem sendo motivo de muita discussão na mídia em geral. Discutimos sobre o termo, sua emergência e também como podemos abordar essa temática nos espaços educativos.

11. Currículo, PPP e educação para a sexualidade: articulações possíveis. Nesta videoaula falamos de currículo e projeto político-pedagógico, estabelecendo algumas relações com a temática do nosso curso: a educação para a sexualidade.

Conforme Aluizio Belizário (2013), a produção de materiais didáticos para cursos online deve ser pensada enquanto elementos ativos e dinâmicos que possibilitem a construção de conhecimentos, além de serem provocadores no processo de comunicabilidade entre os sujeitos participantes do curso.

Assim, o/a cursista que participa do Videocurso, além de assistir as onze videoaulas, participa também de fóruns que buscam problematizar as temáticas presentes nelas. Em um curso oferecido através de um ambiente virtual de aprendizado colaborativo, o fórum pode ser definido como um espaço de discussões em torno dos temas tratados, potencializando o processo de aprendizagem entre todos/as os/as participantes, como também a problematização de pontos de vista entre sujeitos que possuem os mesmos objetivos. 
O fórum promove e também provoca uma ampla discussão sobre algumas temáticas tais como: preconceito, racismo, homofobia, abuso sexual e violência de gênero. Para Faria (2002, 134-135), o fórum "é o lugar para fomentar debates, aprofundar idéias, lançando questões ou respondendo, estimulando a participação e o retorno dos alunos, ficando registradas nominalmente, datadas e visíveis, as contribuições de todos os participantes cadastrados".

No Videocurso os/as cursistas participam dos seguintes fóruns:

Fórum 1: Na videoaula "Identidade e diferença: potencialidades para o debate da diversidade", foi realizada uma discussão sobre a importância do reconhecimento das diferenças, a partir da visibilidade das múltiplas identidades (gênero, sexual, étnico-racial, geracional, classe, regional, entre outras). Boaventura de Souza Santos, em um de seus escritos, coloca: "Lutar pela igualdade sempre que as diferenças nos discriminem. Lutar pela diferença sempre que a igualdade nos descaracterize". A partir dessa colocação, aponte em que momento de sua vida ou de sua atuação profissional você se sentiu discriminado/a ou valorizado/a por suas diferenças.

Fórum 2: Nas videoaulas "Identidades de gênero: masculinidades, feminilidades e suas múltiplas possibilidades", "Identidades sexuais: Refletindo sobre diferentes posições de sujeito" e "Violência de gênero: Sexismo e homofobia" discutimos as identidades de gênero e sexuais e as violências decorrentes dos preconceitos construídos a partir dessas identidades. Temos observado, em diversas pesquisas e reportagens, o número crescente de violências, conforme os dados abaixo. Como você tem percebido essas violências nos espaços sociais em que circula (família, escola, instituições religiosas, redes sociais, universidade, organizações não governamentais, movimentos sociais, entre outros) e que ações podemos desenvolver para o seu enfrentamento? 


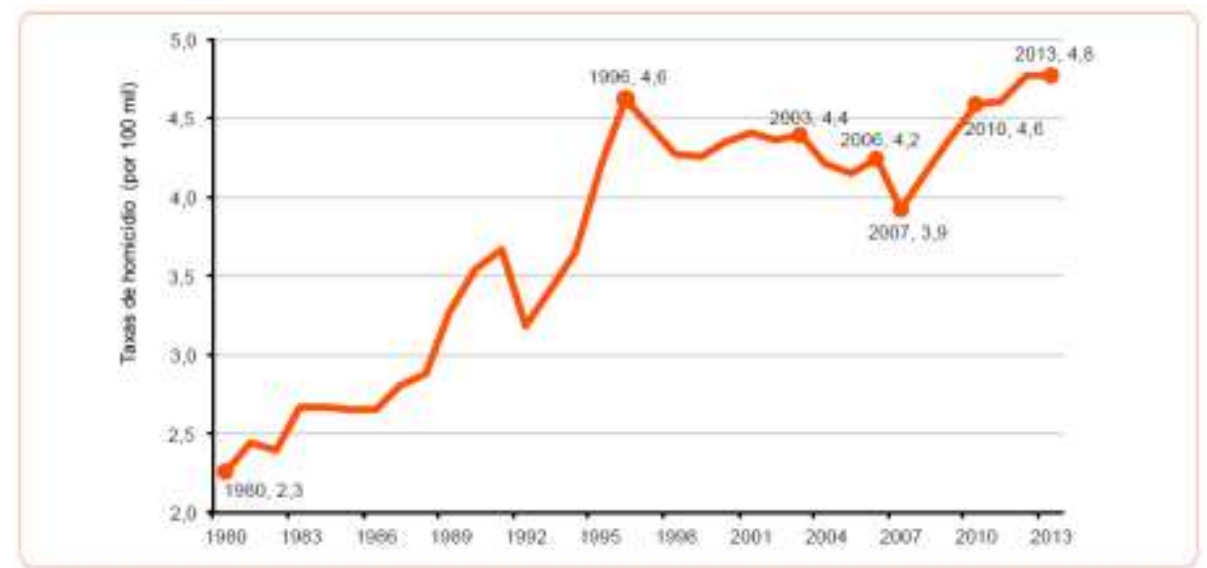

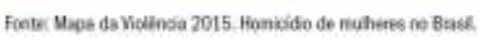

Figura 1: Homicídio de mulheres no Brasil (1980-2013)

\title{
Ideia Legislativa
}

\section{Criminalização da discriminação por orientação sexual e identidade de gênero, equiparando ao crime de Racismo}

\begin{abstract}
Problema :
A população de lésbicas, gays, bissexuais, travestis e transexuais são vítimas das mais variadas formas de violência em razão de discriminação e preconceito por orientação sexual e identidade de gênero. De acordo com o Relatório de Violências Homofóbicas do Governo Federal, são registradas 5 denúncias de violências por dia contra pessoas LGBT, o número de denúncias em 2013 referentes a violações contra a população LCBT aumentou 166\% em relação ao ano anterior. A ONG GCB, apresentou relatório de notícias envolvendo assassinatos de pessoas LCBT, em 2015 foram registradas 1 morte a cada 27 horas. Frequentemente, vimos em noticiários diversos casos, como jovens sendo espancados e expulsos, essa realidade precisa mudar.
\end{abstract}

Figura 2: Criminalização da discriminação por orientação sexual e identidade de gênero, equiparando ao crime de Racismo. Fonte: https://www12.senado.leg.br/ecidadania/visualizacaoideia?id=48820 
Fórum 3: Nas videoaulas "Corpos em Foco: marcadores, inscrições, subjetivações", "Aids: Entendimentos e atualizações" e "Sexting: Possibilidades e discussões" problematizamos que os/as portadores/as do HIV e os/as praticantes de sexting carregam marcas nos seus corpos que os/as posicionam em lugares marginalizados nos meios sociais. Neste fórum gostaríamos que você discutisse os seguintes questionamentos: Como os/as portadores/as do HIV e os/as praticantes do sexting são representados e falados nas diversas mídias? Que medidas de enfrentamento você considera relevantes serem tomadas para que possamos minimizar o preconceito contra os/as portadores/as do HIV e os/as praticantes de sexting?

Fórum 4: Na videoaula "Sexualidade, Gêneros e Mídias: discutindo os artefatos culturais como espaços educativos", abordamos os artefatos culturais enquanto espaços educativos. Assim, nossa proposta neste fórum é instigar você a perceber como as pedagogias culturais estão presentes nos diferentes artefatos que circulam na sociedade. Para tanto, escolha um artefato cultural (revistas, charges, jornais, postagens, vídeos, propagandas, entre outros) e o analise, assim como foi apresentado na videoaula em que discutimos uma cena do filme "A Pequena Sereia". Nessa análise, destaque quais pedagogias estão presentes no artefato escolhido? Que significados sobre os corpos, gêneros e sexualidades estão nele apresentados?

Outra atividade que os/as cursistas têm que realizar como atividade final do Videocurso é a produção de um Recurso Educativo Digital - RED. O RED é um artefato cultural e a produção deste material tem por objetivos possibilitar a organização e construção de recursos didáticos pedagógicos, bem como a socialização de práticas que promovam uma Educação para a Sexualidade no âmbito da escola, utilizando-se das tecnologias digitais de informação e comunicação. A proposta de construir um RED tem por objetivo desenvolvermos algumas estratégias que podem ser utilizadas na sala de aula a fim de promover discussões acerca das temáticas de diversidades, corpos, gêneros e sexualidades. Nesse sentido, o RED pode e deve ser utilizado como uma potente estratégia para a prática pedagógica com relação à problematização da Educação para a Sexualidade.

O RED pode proporcionar uma aprendizagem colaborativa, pois possibilita o desenvolvimento de atividades e trabalhos em grupo à distância; criatividade, pois os diversos recursos tecnológicos permitem que as produções de materiais sejam mais dinâmicas, coloridas e interativas; múltiplas aprendizagens, pois possibilita a aprendizagem tecnológica, interação com diversos equipamentos e linguagens, como musical, imagética e audiovisual; novas alfabetizações, 
sejam elas de tecnologias, de mídias, de informação, de criatividade, de responsabilidade social; convergência com o mundo, ao permitir a interação em qualquer lugar, uma vez que por meio de links e hiperlinks podemos nos conectar com qualquer parte do mundo e, assim, acessar diversas informações; aprendizagem a qualquer hora, em qualquer lugar, pois não precisamos estar juntos/as no mesmo lugar e ao mesmo tempo para aprender uns com os/as outros/as; atualização constante com o mundo, pois as informações podem sempre ser acessadas por todos/as.

A produção do Videocurso tem nos possibilitado ampliar ações e borrar fronteiras geográficas. As interações realizadas com os/as profissionais da educação dos munícipios do Brasil, através dos espaços de debates criados e através da utilização das tecnologias da informação e comunicação, permitem o compartilhamento de saberes e experiências. Além disso, destacamos a importância da formação profissional voltada para a sociedade globalizada em que a comunicação e a informação não se apresentam de forma linear, mas de forma plural, múltipla e complexa, inscritas em redes e conexões, tendo sua responsabilidade e compromisso social ampliados. Sob essa perspectiva, estamos atento a processos que contribuam na formação de profissionais comprometidos com os desafios e exigências deste novo tempo.

\section{NOTAS FINAIS}

A partir das notas apresentadas nessa escrita foi possível perceber o quanto os gêneros e as sexualidades passaram a estar presentes de forma mais específica nas políticas públicas voltadas para o campo da Educação no Brasil, produzindo implicações no espaço escolar e acadêmico. Nossa proposta, então, foi de que pudéssemos pensar os efeitos que esses discursos presentes nestas políticas têm produzido, dentre eles o destaque para pensarmos acerca da importância da promoção de espaços de discussão na formação inicial e também continuada de professores/as a.

As estratégias apresentadas nesse artigo -disciplina e Videocurso- emergiram com o intuito de suscitar esses espaços de discussão. É importante ressaltar que tais ações não se configuram como uma única maneira de promoção do debate sobre gêneros e sexualidades; essas estratégias apresentam-se como possibilidades que nós construímos ao longo de nossa trajetória na formação de professores/as para que essas discussões estejam presentes nas instituições educacionais. 
Pensar a formação inicial e continuada de professores/as tem sido trilhar, muitas vezes, caminhos e descaminhos para que temáticas como os gêneros, as sexualidades, o enfrentamento ao sexismo, a misoginia e à LGBTfobia, as diversas formas de se produzir os corpos e de se vivenciar os prazeres e os desejos, sejam debatidas e incorporadas ao currículo escolar e acadêmico.

Essa incorporação constitui-se como uma das estratégias que poderá contribuir para a minimização dos binarismos (homem/mulher, heterossexual/homossexual, normal/anormal entre outros), dos estigmas, representações e preconceitos atribuídos aos sujeitos que desviam dos padrões socialmente estabelecidos, ou seja, homem branco, jovem, heterossexual, de classe média, cristão.

Entendemos que desconstruir algumas metanarrativas presentes na escola e na universidade talvez nos possibilite construir uma agenda que busque discutir nesses espaços as temáticas relacionadas aos corpos, gêneros e sexualidades, entre tantas outras que não são entendidas como parte do currículo escolar e acadêmico, contribuindo assim para o reconhecimento da pluralidade sexual e de gênero.

\section{REFERÊNCIAS BIBLIOGRAFICAS}

Altmann, H. (2001). Orientação Sexual nos Parâmetros Curriculares Nacionais. Revista Estudos Feministas, 1, 575-585. Recuperado de http://www.scielo.br/pdf/ref/v9n2/8641.

Belisário, A. (2013). Desafios para produção de material didático para a educacãa a distância. En F. Fidalgo, W.J. Corradi, R.N.S. Lima, A. Favacho y E. P. Arruda, Educação a Distancia: Meios, Atores e Processos (pp. 229-241). Belo Horizonte: CAED-UFMG.

Brasil. (1996). Presidência da República. Casa Civil. Subchefia para Assuntos Jurídicos. Lei $n^{\circ}$ 9.394, de 20 de dezembro de 1996. Estabelece as diretrizes $e$ bases da educação nacional. [en línea]. Recuperado de http://www.planalto.gov.br/ccivil_03/leis/19394.htm [Consulta: 28 de abril de 2016].

Brasil. Ministério da Educação. (1997). Parâmetro Curricular Nacional. Apresentação dos Temas Transversais. Ética. [en línea]. Recuperado de http://portal.mec.gov.br/seb/arquivos/pdf/livro081.pdf [Consulta: $28 \mathrm{de}$ abril de 2016].

Brasil. Ministério da Educação. (1997). Parâmetro Curricular Nacional. Orientação Sexual. [en línea]. Recuperado de 
http://portal.mec.gov.br/seb/arquivos/pdf/orientacao.pdf [Consulta: 28 de abril de 2016].

Brasil. Ministério da Educação. (2001). Lei $n^{\circ} 01.0172$, de 9 de janeiro de 2001. Aprova o Plano Nacional de Educação e dá outras providências. [En línea]. Recuperado de http://portal.mec.gov.br/arquivos/pdf/L10172.pdf [Consulta: 29 de abril de 2016].

Brasil. Ministério da Educação. (2014). Plano Nacional de Educação - PNE.

[En línea]. Recuperado de http:/www.planalto.gov.br/CCIVIL_03/_Ato20112014/2014/Lei/L13005.htm [Consulta: 27 de abril de 2016].

Brasil. Ministério da Educação. (2012). Resolução $C N E / C P n^{\circ} 1$, de 30 de maio de 2012. [En línea]. Recuperado de

http://portal.mec.gov.br/index.php?option=com_content\&id=17810\&It emid=866 [Consulta: 27 de abril de 2016].

Brasil. Ministério da Educação. (2002). Conselho Nacional de Educação. Resolução CNE/CP $n^{o} 1$, de 18 de fevereiro de 2002. [En línea]. Recuperado de http://portal.mec.gov.br/index.php?option $=$ com_content\&view $=$ article \&id $=13207 \% 3$ Aresolucao-cp- $2002 \&$ catid $=323 \% 3$ Aorgaosvinculados\&Itemid=866 [Consulta: 28 de abril de 2016].

Brasil. Ministério da Educação. (2012). Conselho Nacional de Educação. Resolução CNE/CP $n^{o}$ 2, de 30 de janeiro 2012. [En línea]. Recuperado de

http://portal.mec.gov.br/index.php?option $=$ com_docman\&view $=$ downl oad\&alias=9864-rceb002-12\&category_slug=janeiro-2012pdf\&Itemid=30192 [Consulta: 28 de abril de 2016].

Brasil. Ministério da Educação. (2015). Conselho Nacional de Educação. Resolução CNE/CP $n^{o}$ 2, de $1^{o}$ de julho de 2015. [En línea]. Recuperado de

http://portal.mec.gov.br/index.php?option $=$ com_docman\&view $=$ downl oad\&alias=17719-res-cne-cp-002-03072015\&category_slug=julho-2015pdf\&Itemid=30192 [Consulta: 28 de abril de 2016].

Baukje, P. y Meijer, I.C. (2002). Como os corpos se tornam matéria: entrevista com Judith Butler. Revista Estudos Feministas, 1, 155-167.

Corazza, S.M. (2002). Labirintos da pesquisa, diante dos ferrolhos. En M.V. Costa, Caminhos Investigativos: novos olhares na pesquisa em educação (pp. 105-132.). Porto Alegre: Mediaçãa.

Escosteguy, A.C.D. (1998). Uma introdução aos Estudos Culturais. Revista FAMECOS, 9, 87-97.

Faria, E.T. (2002). Interatividade e mediação pedagógica em educação a distância. Tese (Doutorado em Educação). Porto Alegre: PUCRS. 
Recuperado de

http://tede.pucrs.br/tde_busca/arquivo.php?codArquivo= $=1330$.

Fonseca, M.A. da. (2003). Michel Foucault e a constituição do sujeito. São Paulo: EDUC.

Foucault, M. (2005). Em defesa da sociedade: curso no Collège de France (19751976). São Paulo: Martins Fontes.

Foucault, M. (2007). Historia da Sexualidade I: a vontade de saber. São Paulo: Graal.

Furlani, J. (2015). Ideologia de gênero? Explicando as confusões teóricas presentes na cartilha. [En línea]. Recuperado de

https://issuu.com/linoperes/docs/_esclarecendo_-_ideologia_de_g_ner

[Consulta: 18 de abril de 2016].

Gallo, S. (2007). Educação menor: produção de heterotopias no espaço escolar. En P.R.C. Ribeiro, M.R.S. Silva, N.G.de Souza, S.V. Goellner y J.F. Souza, Corpo, gênero e sexualidade: discutindo práticas educativas (pp. 93-10). Rio Grande: Ed. da FURG.

Hall, S. (1997). The Work of Representation. En S. HALL, Representation. Cultural Representations and Signifying Practices. London/Thousand Oaks/New Delhi: The Open University.

Junqueira, R. (2014). Conceitos de Diversidade. Parte I. Revista Diversidade e Educação, 3, 4-8. Recuperado de http://issuu.com/gesefurg/docs/diversidadeeducacao03.

Louro, G.L. (2001). Sexualidade e gênero na escola. En S. Schmidt, $A$ educação em tempos de globalização (pp. 69-73). Rio de Janeiro: DP\&A.

Meyer, D.E. (2003). Gênero e educação: teoria e política. En G. L. Louro, J. F. Neckel y S.V. Goellner, Corpo, gênero e sexualidade: um debate contemporañeo na educação (pp. 09-27). Petrópolis: Vozes.

Nelson, C., Treichler, P. A. y Lawrence, G. (2008). Estudos Culturais: uma introdução. En T. T. Silva, Alienígenas na sala de aula. Uma introdução aos estudos culturais em educação (pp. 07-38). Petrópolis: Vozes.

Silva, T.T. da. (2007). Documentos de identidade: uma introdução as teorias do currículo. Belo Horizonte: Autêntica.

Silva, T.T. da (2014). A produção social da identidade e da diferença. En T.T. da Silva, Identidade e diferença: a perspectiva dos estudos culturais (pp. 73-102). Petrópolis: Vozes. 